\title{
Práctica Bélica en la Revolución Novohispana: La Guerrilla del padre José Antonio Torres, 1814-1818*
}

\section{Moisés Guzmán Pérez}

Coordinador del Programa Institucional de Doctorado en Historia en la Universidad Michoacana de San Nicolás de Hidalgo (México) y Profesor adscrito al Instituto de Investigaciones Históricas en la misma institución. Correo electrónico: moisesguzmanp@hotmail.com. El autor es Doctor en Historia por la Universidad de París 1, La Sorbona (Francia). Recientemente ha publicado, entre otros: "El Generalísimo. Configuración, prácticas políticas y representación del poder supremo (México, 1810-1822)", Revista de Indias, Vol. 79 No. 275 (2019); “Cádiz, la insurgencia y el fin del señorío jurisdiccional en Nueva España. El caso de la villa de Charo", Relaciones. Estudios de historia y sociedad, Vol. XXXVIII No. 151 (2017). Entre sus temas de interés se encuentran Historia Política de las Instituciones Militares, Historia de la Guerra, Historiografía Militar.

Recibido: 29 de marzo de 2019

Aprobado: 10 de noviembre de 2019

Modificado: 20 de noviembre de 2019

Artículo de investigación científica

DOI: http://dx.doi.org/10.15648/hc.36.2020.8

* Este artículo forma parte del proyecto "Los Fuertes de la Insurgencia, 1811-1821" financiado por Coordinación de la Investigación Científica de la Universidad Michoacana de San Nicolás de Hidalgo (México).

Esta publicación está bajo una licencia Creative Commons Reconocimiento-NoComercial 4.0 
Práctica Bélica en la Revolución Novohispana: La Guerrilla del padre José Antonio Torres, 1814-1818

\title{
Resumen
}

Este artículo tiene por objeto reconstruir el perfil individual y el activismo político de José Antonio Torres en la revolución novohispana, así como analizar la conformación, estructura y comportamiento de su guerrilla en combate. Se busca superar la visión sesgada y tradicional que ha prevalecido en la historiografía académica, de considerar a Pedro Moreno y a Xavier Mina como los principales caudillos de la resistencia en el Bajío, cuando en realidad el mando principal lo detentaba el padre Torres, y revelar a la vez las variables operativas de la guerra irregular junto con el proyecto político que los insurgentes defendían.

Palabras clave: Independencia, Nueva España, Guerra irregular, Guanajuato, República.

War practice in the new Spain revolution: the "guerrilla" of padre José Antonio Torres, 1814-1818

\begin{abstract}
The purpose of this article is to rebuild the individual profile and the politic activism of José Antonio Torres in the revolution of New Spain. We also analyze the conformation, structure and behavior of Torres' "guerrilla" in combat. The objective is to overcome the biased and traditional vision that prevails in the academic historiography, which considers Pedro Moreno and Xavier Mina as main leaders (caudillos) of the resistance at the Bajío, when actually the main command was in power of priest Torres. We also reveal the operative variables of irregular war and the political project which insurgents wanted to defend.
\end{abstract}

Key words: Independency, New Spain, Irregular War, Guanajuato, Republic.

Prática de guerra na revolução da Nova Espanha: A guerrilha do padre José Antonio Torres, 1814-1818

\section{Resumo}

O objetivo deste artigo é reconstruir o perfil individual e o ativismo político de José Antonio Torres na revolução da Nova Espanha, bem como analisar a conformação, 
estrutura e comportamento de seus guerrilheiros em combate. Busca superar a visão tendenciosa e tradicional que prevaleceu na historiografia acadêmica, de considerar Pedro Moreno e Xavier Mina como os principais líderes da resistência no Bajío, quando, na realidade, o principal comando foi exercido pelo padre Torres, e revelar ao mesmo tempo, as variáveis operacionais da guerra irregular assim como o projeto político que os insurgentes defendiam.

Palavras-chave: Independência, Nova Espanha, Guerra irregular, Guanajuato, República.

Les pratiques de guerre à la révolution de la Nouvelle-Espagne: la «guerrilla» du prêtre José Antonio Torres, 1814-1818

\section{Résumé}

L'objectif de cet article c'est reconstruire le profile individuel et l'activisme politique de José Antonio Torres à la révolution de la Nouvelle-Espagne ; nous voulons aussi analyser la conformation, la structure et le comportement de sa "guerrilla » en combat. Nous essayons de surmonter la vision partielle et traditionnelle qui a prévalu dans l'historiographie académique, et qui considère Pedro Moreno et Xavier Mina comme les principaux chefs de guerre de la résistance au Bajío, quand en réalité, le charge principal appartenait au prêtre Torres ; nous allons révéler aussi les variables opérationnelles de la guerre irrégulière et le projet politique qui était défendu par les insurgés.

Mots clé: Independence, Nouvelle Espagne, Guerre irrégulière, Guanajuato, République.

\section{INTRODUCCIÓN}

Uno de los aspectos menos estudiados por la historiografía que se ocupa de la revolución novohispana, es aquel que se refiere a las prácticas bélicas y las formas de hacer la guerra, particularmente durante los años de 1814 a 1820 que corresponden al llamado sexenio absolutista. Últimamente, los historiadores que se ocupan de lo militar han insistido en abordar esta problemática no sólo desde los aspectos tácticos, estratégicos, logísticos y orgánicos, sino también desde el acto operacional mismo, la naturaleza de las maniobras y las formas en que se ha hecho la 
guerra en cada época histórica. Para el tema que nos ocupa, un análisis desde esa perspectiva puede ayudar a comprender mejor la complejidad de la resistencia armada, permite visibilizar sus componentes sociales, descubrir los distintos escenarios de lucha entre insurgentes y realistas, y explicar por qué razones el conflicto se prolongó más tiempo en determinadas regiones del país.

Sin duda hubo cambios en las formas de combatir con el retorno al absolutismo, pero los estudiosos de la Independencia durante los años de la Restauración se han centrado en el análisis de otros temas y han obviado el aspecto propiamente guerrero y armamentista del conflicto, con todo lo que ello implica. Para el caso novohispano, lo cotidiano ya ha sido abordado recientemente, así como la supervivencia de ciertas instituciones y postulados liberales que dejaron su impronta en los años del sexenio ${ }^{1}$; también se ha analizado la militarización que sufrió la estructura de gobierno y la sociedad en general como mecanismos de autodefensa, junto con los nuevos marcos de referencia doctrinarios y propagandístico empleados y difundidos por los antiguos vasallos de la Monarquía para legitimar el retorno del Antiguo Régimen². Sin embargo, faltan estudios serios sobre lo ocurrido con las insurgencias en esos años, que superen la visión simplista del caos y el desorden causado por la guerra de guerrillas y el gobierno decadente, tesis difundida por Lucas Alamán desde el siglo XIX y retomada sin mayor crítica por la historiografía contemporánea; eso quizás explique por qué la guerra no terminó en 1815 con la ejecución de José María Morelos.

El presente artículo tiene por objeto: reconstruir el perfil y la trayectoria militar del clérigo insurgente José Antonio Torres, tratando de precisar la jerarquía que alcanzó durante la guerra; analizar la estructura y composición social de su guerrilla; determinar sus bases sociales de apoyo,

1 Iliria Olimpia Flores Carreño, Vida cotidiana y violencia durante la guerra de independencia. Guanajuato y Michoacán, 1800-1830 (México: Fórum Cultural Guanajuato, 2018); José Antonio Serrano Ortega (coord.), El sexenio absolutista, los últimos años insurgentes Nueva España (1814-1820) (México: El Colegio de Michoacán, 2014).

1722 Rodrigo Moreno Gutiérrez, "La Restauración en la Nueva España: Guerra, cambios de régimen y militarización entre 1814 y 1820”, Revista Universitaria de Historia Militar Vol. 7 No. 15 (2018): 101-125; Josep Escrig Rosa, "La construcción ideológica de la Restauración en Nueva España (18141816)”, en Historia Mexicana T. LXIX No. 4 (2000): 1493-1548. 
ancladas en innumerables pueblos, haciendas y ranchos del Bajío; conocer las principales fuentes de ingreso disponibles y la manera en que se hizo con el control de los recursos; ahondar en el funcionamiento de su práctica bélica con base en sus variables operativas, y finalmente, hacer hincapié en el proyecto político republicano que defendía y que lo motivó a él y a su gente, a mantenerse en pie de lucha.

\section{Perfil e inicios como insurgente}

José Antonio Torres Torres nació en la hacienda de Atzimbo, jurisdicción de la ciudad de Tzintzuntzan, Michoacán, por el año de 1780. Fue el primogénito de una familia de diez hermanos, seis hombres y cuatro mujeres que procreó el enlace matrimonial de Salvador Torres Arroyo con María Juliana Torres Alejandre. Luego de recibir la primera instrucción en su tierra natal, de joven fue inscrito en el Seminario Tridentino de san Pedro, en Valladolid de Michoacán y hacia 1806 inició su carrera sacerdotal. Fue subdiácono, diácono y presbítero; para julio de 1809 comenzó a fungir como teniente de cura en la capilla de Cuitzeo de los Naranjos (hoy Abasolo, Gto.), y para marzo del año siguiente tenía licencia para celebrar misa, confesar hombres y administrar los servicios religiosos a las mujeres que vivían en Pénjamo. Sería pues, en Cuitzeo de los Naranjos, donde lo sorprendería la insurrección ${ }^{3}$.

Tal como sucedió con varios clérigos de la extensa diócesis de Michoacán, el padre Torres se adhirió a la lucha armada temeroso de perder su religión, su rey y su patria, pero no lo hizo inmediatamente, sino hasta unos meses después de que aquella comenzara. Es probable que también haya estado en contra del gobierno de la Regencia -conocía sus impresos-, igual que lo estuvieron otros curas michoacanos contemporáneos a él, como Luciano Navarrete, José Guadalupe Salto o Rafael García de León, por citar algunos ${ }^{4}$. De lo que no cabe duda es que

3 "Instrucción de Juan Antonio de Tapia" (Valladolid, 10 de julio de 1805), en Archivo Histórico Casa de Morelos (AHCM). Diocesano. Gobierno, Sacerdotes, Nombramientos, años 1800-1805, caja 471, carpeta 6; Cabildo eclesiástico, (Valladolid, 14 de marzo de 1807), en AHCM. Diocesano, gobierno, registros, correspondencia, 1806-1808, caja 328, carpeta 5.

4 Moisés Guzmán Pérez, El insurgente José María Guadalupe Salto. Vida y martirio (México: Secretaría de Cultura, Gobierno del Estado de Michoacán, Secretaría de Turismo y Cultura, H. Ayunta- 
estaba perfectamente enterado de los sucesos ocurridos en la Península cuando Fernando VII cayó en manos de Napoleón; estuvo al tanto de la aprehensión del virrey José de Iturrigaray por los "gachupines" de la Ciudad de México, "siendo esta autoridad legítima y constituida por el rey”, decía en una carta; tenía clara la usurpación de los derechos de los americanos, al no permitírseles crear su propia junta gubernativa en ausencia del soberano, y estuvo al tanto de los decretos expedidos por las Cortes españolas desde la Península 5 .

Algunos autores sostienen que peleó contra los realistas en Valladolid de Michoacán en junio de $1811^{6}$, lo cual es bastante probable, pues para septiembre siguiente otro comandante al servicio del rey, Joaquín del Castillo y Bustamante, dice que incursionaba por el rumbo de La Alberca y el Puerto de Zipimeo al lado del cura Luciano Navarrete, aunque confundiéndolo con un "arriero" confusiones en autores como Villaseñor y Villaseñor, que consideran que se trataba del "amo" José Antonio Torres, aquel hombre originario de San Pedro Piedra Gorda (hoy Manuel Doblado, Gto.), mayordomo de hacienda que tomó la ciudad de Guadalajara a finales de 1810.

También se ha divulgado la noticia de que el padre Torres actuaba al lado del célebre guerrillero Albino García, alias "el manco García”, quien desde fecha muy temprana incursionó por el Bajío guanajuatense, pero el historiador Fernando Osorno no lo consigna en su obra. En cambio, demuestra con documentación inédita y original que las fuerzas de este genial guerrillero eran dirigidas por los cabecillas Escandón, los González, Tomás Baltierra "Salmerón”, Anacleto Camacho, los Pes-

miento de Morelia, Instituto de Investigaciones Históricas, Universidad Michoacana de San Nicolás de Hidalgo, 2012), 81.

5 "Carta de Torres a Negrete (Pénjamo, 13 de julio de 1814)", en Colección de documentos para la historia de la guerra de independencia de México de 1808 a 1821, Juan E. Hernández y Dávalos (México: Instituto Nacional de Estudios Históricos de la Revolución Mexicana, 1985), VI, 229.

6 Alejandro Villaseñor y Villaseñor, Biografías de los héroes y caudillos de la independencia (México: Jus, 1963) II, 161.

7 Moisés Guzmán Pérez, El insurgente, 97. 
cadores, Marcelo Valero “el Negro” y otros jefes que se sumaron a su partida como Portugal, Navarro y Villaseñor ${ }^{8}$.

Al menos desde junio de 1811 el padre Torres estaba activo en la guerra. Es probable que haya tomado partido por la insurrección cuando supo que los comandantes realistas estaban retirando a los párrocos del seno de sus feligresías, como ocurrió en los pueblos de Yuriria, Valle de Santiago, Huaniqueo, Pénjamo, Cuitzeo y algunos otros de aquella demarcación. La medida fue calificada por el doctor José María Cos, vicario general castrense del gobierno insurgente, como inhumana e irreligiosa porque dejó a los creyentes sin pastor, los privó del uso de los sacramentos "y de todos los auxilios de religión y de piedad que la Iglesia proporciona a sus hijos") .

Antes de que terminara el año de 1812, el padre Torres ostentaba ya el grado de coronel, título que le debió ser conferido por José María Liceaga, vocal y capitán general de la Suprema Junta Nacional Americana. Sabemos que intentó ganarse la voluntad de Ignacio Rayón, presidente de aquel gobierno, pues desde el 8 de enero de 1813 el secretario Ignacio Oyarzábal llevaba consigo un "batón” (sic por bastón) que le había remitido dicho coronel, pero no se sabe qué respuesta dio el abogado a este obsequio ${ }^{10}$.

El padre Torres comenzó a figurar de manera importante en la revolución a partir del primero de mayo de 1813 cuando el propio Liceaga, en su carácter de capitán general, nombró a José María Cos su segundo "para que en caso de muerte u otra contingencia le suceda, y a éste le

8 Fernando Osorno, El insurgente Albino García (México: Secretaría de Educación Pública, 1982), 167 , nota $3 ; 253$.

9 “Semanario Patriótico Americano, No. 7 (Tlalpujahua, Michoacán 30 de agosto de 1812)”, en Documentos históricos mexicanos, Genaro García (México: Instituto Nacional de Estudios Históricos de la Revolución Mexicana, 1985), III, 74.

10 “Oyarzábal a Rayón (Hacienda de Solís, 8 de enero de 1813)”, en Prontuario de los insurgentes. Introducción y notas, ed. Virginia Guedea (México: Centro de Estudios sobre la Universidad, Instituto Mora, 1995), 335. 
subroga y nombra de su tercero para iguales casos a don José Antonio Torres, brigadier"'11.

\section{Nuevos ascensos militares del Padre Torres}

De que el padre Torres estuvo enterado de la campaña que Morelos emprendería sobre Valladolid en diciembre de 1813, no cabe la menor duda. En la tercera semana de enero de 1814 Torres le envió una carta al generalísimo diciéndole que estaba muy pendiente de sus movimientos y que aguardaba "sus soberanas órdenes", o en su defecto, las del teniente general Manuel Muñiz. Además, le pedía que regresara José María Liceaga a la provincia de Guanajuato, pero no en calidad de diputado por aquella provincia, sino como comandante de armas y para ello elogiaba todos sus méritos ${ }^{12}$. El nuevo virrey Félix María Calleja estaba convencido que las fuerzas de Fernando Rosas marcharían a reunirse con Morelos en el mes de diciembre, previo al ataque de Valladolid, figurando entre ellos el fraile franciscano Monterde, Gabriel Ornelas, Manuel Flores, Juan Sein y Salvador Carranco, que habían sido indultados en Guanajuato y volvieron a unirse a la insurgencia ${ }^{13}$.

Sin embargo, con la derrota del Ejército del Sur en las cercanías de Valladolid en diciembre de 1813, y luego en Puruarán en enero de 1814, la situación cambió radicalmente para la insurgencia. Fue entonces que el doctor José María Cos "en uso de las facultades amplias que el Soberano Congreso Nacional” le había conferido como comandante de armas, se constituyó en coronel de un cuerpo distinguido de patriotas que tenía por objeto "promover la justa causa de la nación". Además, nombró tenientes coroneles a varios jefes insurgentes: al teniente general Manuel Muñiz para la intendencia de Valladolid; al brigadier José María Vargas para la Nueva Galicia; al brigadier José Antonio Torres para la de Guanajuato; al coronel Víctor Rosales para la de Zacatecas y al coronel Fernando Rosas para la de San Luis Potosí1 ${ }^{14}$.

11 "Decreto de Liceaga (Valle de Santiago, $1^{\circ}$ de mayo de 1813)", en Prontuario, ed. Virginia Guedea, 283.

12 “Torres a Morelos (Pénjamo, 24 de enero de 1814)", en Prontuario, ed. Virginia Guedea, 463.

13 "Calleja a Iturbide (México, 20 de abril de 1814)", en Boletín del Archivo General de la Nación. Vol. XI, T. II (1926): 39-40.

14 "Decreto de Cos (Ario, 2 de abril de 1814)", en Prontuario, ed. Virginia Guedea, 515. 
Al menos hasta mayo de 1814 Torres conservó su título de brigadier. Hay evidencias de que semanas antes de la fecha señalada, había ordenado que el también brigadier Tomás Baltierra "Salmerón” fuera decapitado por insubordinación, por no obedecer sus órdenes y por haber apoyado a Ignacio Rayón en el pleito que surgió entre este y los vocales Berdusco y Liceaga, capitanes generales de la Suprema Junta; la misma suerte corrió el coronel Alejandro Nájera por órdenes del doctor José María $\operatorname{Cos}^{15}$.

A partir de entonces, Torres se convirtió en el jefe militar más connotado en todo el Bajío, una región que grosso modo comprendía lugares como Celaya, Acámbaro, Silao, Irapuato, Salamanca, Yuriria y Pénjamo, caracterizados todos ellos por su notable crecimiento poblacional, su pujante industria interna y su enorme desarrollo agrícola y ganadero, al grado de constituirse en el granero de la Nueva España. Su importancia geoestratégica era incuestionable. Desde Guanajuato, ciudad capital de aquella provincia y muy famosa por sus ricos yacimientos mineros, se desprendían tres importantes vías de comunicación que conectaban al norte con Zacatecas, al poniente con Guadalajara, capital de la Nueva Galicia, y al oriente con la vasta intendencia de San Luis Potosí, cuya población extendía sus vínculos comerciales con las provincias internas, por el empleo que generaban para los trabajadores textiles y los artesanos urbanos, así como para los labradores agrícolas ${ }^{16}$. En otras palabras, Torres actuaba en el corazón del virreinato y desde allí disputaría al coronel realista, Agustín de Iturbide, el control y acopio de recursos ${ }^{17}$.

La fama y correrías del padre Torres por la intendencia de Guanajuato llegaron a oídos de José María Morelos, quien no tardó en reconocer sus méritos. En una carta dirigida a Rayón desde su cuartel general en Agua Dulce de fecha 24 de julio de 1814, le informaba que en su calidad de

15 Liceaga a Salmerón (Valle de Santiago, 28, 30 de abril de 1813), en Virginia Guedea, Prontuario, 22; Muñiz a Morelos (Chupio, 18 de mayo de 1814), en Virginia Guedea, Prontuario, 326.

16 P. J., Bakewell, Minería y sociedad en el México colonial. Zacatecas, 1546-1700 (México: Fondo de Cultura Económica, 1976), 87-95; David Brading, Haciendas y ranchos del Bajío. León 1700-1860 (México: Grijalbo, 1988), 57-59.

17 Joaquín E. Espinoza Aguirre, "La angustiada situación y nunca vista escasez. La guerra de independencia en la provincia de Guanajuato (1810-1816)", Bicentenario. Revista de historia de Chile y América Vol. 17 No. 1 (2018): 55-89. 
generalísimo, había concedido asensos militares a varios comandantes de armas, entre los cuales se encontraba el padre José Antonio Torres, que había sido agraciado con el título de mariscal de campo ${ }^{18}$. De esta manera, su nombre se sumaba a la larga lista de nombramientos militares concedidos por la dirigencia insurgente desde Acámbaro en 1810.

Mucho influyó en la decisión de Morelos la respuesta que el padre Torres dio a la carta que le remitió Pedro Celestino Negrete, acompañada de un ejemplar de la Gaceta, anunciándole el regreso de Fernando VII al trono de España. En ella cuestionó de forma enérgica tal atrevimiento y advirtió de forma irónica "las plausibles consecuencias de la venida de Fernando" y su gobierno monárquico, que desconoció la legitimidad de las Cortes. Pero además, era una forma de agradecerle por servir de intermediario para el envío de una imprenta que le mandaron los Guadalupes desde México, junto con oficiales y operarios que puso a trabajar en el pueblo de Atijo, al sureste de la tierra caliente de Michoacán ${ }^{19}$.

No es posible determinar el origen geográfico de los hombres que acompañaban a los distintos jefes rebeldes, mucho menos fijar el porcentaje de población de cada provincia que se sumó a la insurgencia, como pudiera pensar el lector más exigente; el mismo Brading ha señalado para la jurisdicción de León, que el número de matrimonios no siempre coincide con la información matrimonial de los registros estudiados; que un quinto de todos los adultos hombres no eran originarios de Guanajuato y que con la rebelión, mucha gente debió emigrar a lugares circundantes ${ }^{20}$. Por tanto, nos limitaremos a señalar en números absolutos la cantidad de hombres que los jefes mandaban.

18 Morelos a Rayón (Agua Dulce, 24 de julio de 1814), en Virginia Guedea, Prontuario, 106.

19 "Carta del padre Torres a Pedro Celestino Negrete" (Pénjamo, 13 de julio de 1814), en AGN, Historia, Vol. 116, f. 297r-300r. Juan E. Hernández y Dávalos, Colección, VI, No. 258 (sic), 228-231; Lucas Alamán, Historia de Méjico. Desde los primeros movimientos que prepararon su independencia en el año de 1808 hasta la época presente (México: Fondo de Cultura Económica, Instituto Cultural Helénico, 1985), IV, 160; Informe de un espía realista (Apatzingán, 20 de agosto de 1814), en Ernesto Lemoine Villicaña, Morelos. Su vida revolucionaria a través de sus escritos y de otros testimonios de la época. (México: Universidad Nacional Autónoma de México, 1965), 480.

David Brading, Haciendas y ranchos, 99. 
La fuerza del padre Torres la conformaban alrededor de 1,500 hombres que actuaban en pequeñas guerrillas por toda la provincia, sólo comparable al mismo número que mandaba Manuel Muñiz en Michoacán; era superior a los 1,000 efectivos dirigidos por los clérigos Luciano Navarrete y Francisco Sáenz, y apenas superadas por los 1,800 que comandaba José María Vargas en la Nueva Galicia y los 2,000 del propio José María Morelos en el sur del país ${ }^{21}$.

La prueba de fuego para Torres se presentó en la primera semana de diciembre de 1814 cuando reunió a sus hombres en la hacienda de Cuerámaro, incluidos aquellos que actuaban fuera de su demarcación. Además de la gente que el propio Torres mandaba, el día 8 asistieron las fuerzas de Fernando Rosas, Lucas Flores, Cruz Arroyo, Manuel Cabeza de Vaca, el padre Pedro Uribe, José María Contreras, casi toda la de José María González Hermosillo mandada por su segundo Rodríguez conocido por el alias de "el terracalenteño"; la del padre Francisco Sáenz con otras pequeñas capitaneadas por "el gran Liceaga"22. Iturbide trató de sorprenderlos y los tuvo "en alarma continua en la falda del cerro de la misma hacienda...", y a pesar de las maniobras que realizó el teniente coronel Mariano Rivas con la artillería e infantería, "no tuvo este plan todo el buen efecto que debía" porque "la profundidad de las barrancas, la muchedumbre de peñascos y la espesura de árboles en partes libertaron la vida a muchos perversos; murieron pocos; se cogieron 9 prisioneros, entre ellos al mal eclesiástico padre Sáenz que se decía brigadier [y a la fuga de Liceaga y Torres que cuidan escrupulosamente de su existencia sin buscar fútiles blasones de valentía] quedó mandando la acción. Se tomó el cañón que tenían, 9 cajones de cartuchos de él y de fusil, 16 fusiles, algunas lanzas, machetes y caballos"23. Andrés Terrés y Masaguer recuerda que "después de la acción de la hacienda de Corralejo, [Sáenz] tomó chocolate con Iturbide tratándose ambos con la familiaridad que tenían cuando eran condiscípulos, les acompañábamos

21 Francisco Menocal a Manuel Abad y Queipo (Valladolid, 31 de agosto de 1814), en Ernesto Lemoine Villicaña, Morelos. Su vida, 487.

22 "Iturbide a Calleja (Corralejo, 12 de diciembre de 1814)", en Boletín del Archivo General de la Nación, Vol. XI T. II (1926): 300-303.

23 "Iturbide a Calleja (Corralejo, 12 de diciembre de 1814)", en Boletín del Archivo General de la Nación, Vol. XI T. II (1926): 300-303. 
el coronel Ponce y yo, y, al dar las doce de la noche, el padre Sáenz fue fusilado sobre un muladar de la hacienda por orden de su colega"24.

En algún momento del año de 1815 o principios de 1816, el padre Torres comenzó a ser reconocido como "teniente general graduado" por la Junta Subalterna Gubernativa, aquel órgano de gobierno creado por el Supremo Congreso Mexicano en Uruapan en septiembre de 1815, lo cual quería decir que ya para entonces Torres había participado en acciones militares de cierta relevancia y que desempeñaba funciones mucho más allá de lo que su grado original de mariscal de campo le exigía.

\section{Estructura de la guerrilla}

Fue común que los mariscales de campo que servían al Gobierno Provisional Mexicano designaran a algún coronel como su "segundo", cuyos nombramientos eran realizados frente a la tropa y posteriormente ellos mismos gestionaban los despachos ante el Gobierno Provisional. Los nombramientos se realizaban jerárquicamente, con base a Ordenanza ${ }^{25}$, de acuerdo con la trayectoria y los triunfos alcanzados en campaña. De esta manera se garantizaba la continuidad del mando en cada demarcación y se mantenía la subordinación de las fuerzas que servían a cada jefe en caso de muerte. Una persona apellidada Rodríguez a la que apodaban "el terracalenteño", era segundo de José María González Hermosillo'o; en noviembre de 1815 la Junta Subalterna designó al mariscal de campo Mariano Carmona segundo del comandante José Manuel Correa ${ }^{27}$; el coronel José María Carmonal era segundo de Benedicto López ${ }^{28}$; y Manuel Cabeza de Vaca fue nombrado sucesor del

24 Andrés Terrés y Masaguer, "Diario de Campaña”, en Diarios Expedición de Mina. México (1817), eds. James A. Brush, James Morris Webb, John Bradburn, Andrés Terrés y Masaguer (México: edición de Manuel Ortuño Martínez. Madrid: Trama Editorial, 2011), 218.

25 Ordenanzas militares del rey Carlos III, (1768).

26 "Iturbide a Calleja (Corralejo, 12 de diciembre de 1814)", en Boletín del Archivo General de la Nación, Vol. XI T. II (1926): 300-303; además: Gaceta del Gobierno de México, T. VI, No. 682, México, jueves 12 de enero de 1815, 33-38; Lucas Alamán, Historia de Méjico. Desde los primeros, IV, 204205.

18027 José Antonio Serano Ortega, "Dolores después del Grito. Estrategias militares insurgentes y realistas en el norte de Guanajuato, 1810-1821", Tzintzun. Revista de Estudios Históricos No. 61 (2015): 34-35.

28 "Benedicto López al excelentísimo señor presidente y vocales del Gobierno Provisional" (Campo en Las Mojarras, 14 de abril de 1817), en Gaceta del Gobierno Provisional Mexicano en las Provincias 
padre José Antonio Torres, en caso de que este llegara a faltar ${ }^{29}$. Como vemos, un mariscal de campo siempre fue más que un coronel.

La capacidad de liderazgo del padre Torres en la región del Bajío se puede observar a través de los jefes y oficiales que estaban subordinados al Gobierno Provisional Mexicano, pero que rendían sus partes militares al mariscal de campo oriundo de Tzintzunzan. Figuran entre ellos tres brigadieres: Víctor Rosales, José María Nieves Huerta y Pedro Moreno; cinco coroneles: Miguel Borja, Mariano Borja, Mariano Carmona, Manuel Vargas Machuca y Lucas Flores; dos capitanes: Florencio Dueñas y Pío González, además de José Antonio Morrás, que aparece sin grado.

Cada uno de estos oficiales superiores, jefes y oficiales mantenía su propia estructura basada en la jerarquía castrense impuesta por las Ordenanzas militares de España, aquellas que hizo publicar el rey Carlos III en dos tomos en 1768. A eso se debe que ciertos jefes y oficiales de cierta importancia no aparezcan directamente subordinados a Torres. Son los casos del coronel Encarnación Ortiz, uno de los "pachones" y del capitán Andrés Delgado "el Giro", que actuaban bajo el mando del coronel Mariano Carmona ${ }^{30}$.

Por otro lado, la partida que comandaba el padre Torres se componía de dos coroneles: Manuel Cabeza de Vaca y Pedro Uribe; cuatro capitanes: Cruz Arroyo, Francisco Texeda, Miguel Villegas y Miguel Torres; finalmente, tres individuos que aparecen sin grado: José María Negrete, José Antonio López de Lara y José María Sixtos. Resulta interesante conocer los antecedentes de los integrantes de su guerrilla. Sus dos coroneles por ejemplo, tenían empleos diferentes: mientras Cabeza de Vaca se desempeñaba desde antes de 1810 como teniente del Regimiento de la Reina y participó de las reuniones conspirativas al lado de Ignacio Allende, sumándose de inmediato a la insurgencia bajo las órdenes de José María González Hermosillo, hasta alcanzar el grado de coronel;

del Poniente (GGPMPP), T. I, No. 4. (Jaujilla, Michoacán, domingo 20 de abril de 1817), en Genaro García Documentos, IV, 13-14.

(Jaujilla, Michoacán, lunes 21-III-1817), GGPMPP, T. I, No. 2, 6-8, en Genaro García, Documentos, IV.

30 Virginia Guedea, Prontuario, 106. 
Uribe era sacerdote de la diócesis de Michoacán y quedó al frente de las fuerzas que comandaba Domingo Segura, muerto por los realistas en una acción. Desde junio de 1814 actuaba a la cabeza de 500 hombres, razón por la cual una de sus hermanas fue capturada y encerrada en la casa de Recogidas de Guanajuato ${ }^{31}$.

Respecto a los capitanes subordinados a Torres, su pasado es un tanto obscuro. De Cruz Arroyo se sabe que fue el responsable de incendiar la hacienda de San Antonio por órdenes superiores, quizá del mismo padre Torres y que para el primer trimestre de 1817 había alcanzado el empleo de capitán, distinguiéndose por su valor en el ataque a la ciudad de Pátzcuaro. Francisco Texeda quizá era hermano de Cayetano, del mismo apellido, aquel que ostentara el cargo de coronel del Regimiento de la Buena Suerte, aprehendido en el pueblo de Puruándiro y fusilado por el coronel realista Felipe Castañón el 2 de noviembre de 1814. Francisco figura por primera vez como apoderado del coronel Manuel Vargas Machuca en las asambleas celebradas en el Fuerte de los Remedios a finales de noviembre de 1816, a las que también concurrieron: José Antonio Torres, Víctor Rosales y Francisco Loxero, en las cuales Texeda presentó plan de gobierno ${ }^{32}$. El parte militar del padre Torres señala que se distinguió en la acción que los insurgentes tuvieron en la ciudad de Pátzcuaro frente a los realistas en marzo de $1817^{33}$.

De Miguel Villegas sólo se sabe que tenía el grado de capitán y que en marzo de 1817 había participado en el ataque a la ciudad de Pátzcuaro, distinguiéndose "con particularidad", según informó el padre Torres al presidente y vocales del Gobierno Provisional desde el campo general en el Llano del Cuatro el 13 de marzo de aquel año. El último de los capitanes, Miguel Torres, era hermano menor del padre José Antonio Torres. Participó en la mencionada acción de Pátzcuaro en marzo de de 1935): 86-87.

33 (Jaujilla, Michoacán], lunes 21-III-1817), GGPMPP, en Genaro García, T. I, No. 2, 6-8, Documentos, IV. 
1817 y años más tarde, fue quien quitó la vida al capitán insurgente Juan Zamora, por asesinar a su hermano mayor ${ }^{34}$.

En cuanto a los otros tres individuos que aparecen sin grado militar, se sabe que José María Negrete era el encargado de dirigir la tropa de reserva en los ataques que emprendía el padre Torres; José Antonio López de Lara, por su parte, fungió como apoderado del brigadier José María Nieves Huerta en las asambleas que tuvieron lugar en la Fortaleza de Los Remedios en noviembre de 1816 con la finalidad de reorganizar los planes del gobierno insurgente. López de Lara dijo
"que aunque no ha asistido a las anteriores sesiones tiene luces de este negocio, ha oído las actas que se le leyeron en esta asamblea y le pare- ce muy bien lo resuelto en el acta precedente, por ser muy conforme a sus ideas liberales que siempre ha deseado en el gobierno que deba establecerse, y que en lo sucesivo votará con franqueza lo que le dicte su conciencia" 35 .

Era el encargado de defender uno de los baluartes en el fuerte de Los Remedios, según se aprecia en el mapa del fuerte del cerro de San Gregorio. Así mismo, será el principal responsable de la defensa del Fuerte de Jaujilla, asediado por las tropas de Pascual Liñán en el primer trimestre de $1818^{36}$. Finalmente, José María Sixtos era un clérigo de la diócesis de Michoacán, originario de Guanajuato, hijo de José Sixtos y Juana Villaseñor. Fue colegial teólogo en el real y primitivo colegio de San Nicolás Obispo, discípulo de Francisco Argándar y sinodado de Antonio María Uraga. En agosto de 1806 optó al subdiaconado, luego al diaconado hasta ordenarse presbítero ${ }^{37}$. Por el sólo hecho de ir a oficiar misa a Pueblo Nuevo, en las inmediaciones de Puruándiro el 9 de abril de 1815, su madre (Juana Villaseñor) y su hermana (María Josefa) fueron detenidas. Temeroso de correr la misma suerte, dejó el curato

34 Lucas Alamán, Historia, IV, 634-635; Genaro García, Documentos, V, 433; José María Miquel i Vergés, Diccionario de insurgentes, 572.

35 "El Fuerte de los Remedios", 91.

36 José Miquel, Diccionario de insurgentes, 335-336.

37 "Expediente del bachiller José María Sixtos" (1806), en AHCM. Diocesano, Gobierno, Seminario, órdenes, caja 572, carpeta 60. 
que atendía y se unió a las fuerzas del padre Torres ${ }^{38}$. También fue el responsable de defender uno de los baluartes en el fuerte de Los Remedios, según se observa en el plano que existe en el Archivo General de la Nación de la Ciudad de México.

\section{LaS bases SOCIALES DE APOYO}

Para sostener económica y militarmente el movimiento, el padre Torres contó con la ayuda de tesoreros, administradores, subdelegados, comisionados y emisarios que desempeñaron una variedad de funciones. Actuaban desde los mismos pueblos, haciendas y ranchos controlados por la insurgencia, cuidando de no permanecer por mucho tiempo en un punto fijo. En otras ocasiones se introducían en villas y ciudades en busca de dinero u objetos de valor, y hasta hacían las veces de espías e informantes. Las razones de estos apoyos no están del todo claras; lo que indican las fuentes es que las personas lo hacían por lealtad y sumisión a sus jefes, por creer en la causa que defendían como "hombres libres" y sobre todo por demostrar su "patriotismo", como exigía el capítulo VI, artículo 41 de la Constitución de Apatzingán, que habían jurado $^{39}$; pero no pocos de ellos ofrecieron su apoyo para no perder sus animales y pertenencias, sufrir las represalias de los jefes y oficiales subordinados o incluso perder la vida.

Fue bastante significativo el respaldo que obtuvo el padre Torres de lo que podríamos llamar el sector popular: se cuentan entre ellos artesanos, trabajadores del campo y operarios de las minas que se vieron obligados a migrar, estableciéndose en lugares más seguros, como León, por ejemplo, desde donde continuaron ofreciendo su apoyo de muy diversa manera, como bien lo detectaron los comandantes realistas. La ayuda provenía incluso de la provincia de Michoacán, de la zona de donde Torres era originario. Los rancheros y los indios de los pueblos de la ribera del lago de Pátzcuaro, le ayudaban en la recaptura de algunos prófugos, y el propio Mina, días antes de ser fusilado, dijo a un

39 Decreto Constitucional para la Libertad de la América Mexicana sancionado en Apatzingán a 22 de octubre de 1814. (Apatzingán: Imprenta Nacional, 1814), 8. 
oficial realista que "los indios y mulatos que están a sus órdenes le besan la mano" ${ }^{40}$. Esto nos permite apreciar, más allá de sujetos concretos no siempre fáciles de identificar, la calidad étnica y el tipo de personas que le franqueaban su ayuda.

En infinidad de ocasiones, los subordinados del padre Torres fungían como informantes. Desde el Aguacatito, el capitán José Texeda le enviaba cartas al clérigo michoacano avisándole de los movimientos de las tropas del rey con la finalidad de preparar oportunamente las emboscadas o bien para evitar cualquier desaguisado. Bernardo Yarza por su parte, hacía lo propio sobre lo acontecido por el rumbo de Xalpa, en donde estaba al mando; y Luciano Navarro le escribía a Torres suplicándole que le diera destino ${ }^{41}$. Una anciana informó a los realistas que, para advertir a los comandantes sobre los movimientos de las tropas enemigas, los capitanes insurgentes ordenaban prender fuego a los ranchos y el humo generado les servía de "telégrafo". Entonces los realistas ordenaron quemar varios jacales para confundir a los rebeldes y procurar su captura, como ocurrió con la del capitán Carrillo en la cofradía llamada de Marañón ${ }^{42}$.

A aquellos que se distinguían en acciones frente a los realistas, el padre Torres los premiaba concediéndoles ascensos militares, como fue el caso de Estanislao Tovar a quien concedió el empleo de coronel por capitanear desde 1814 una partida insurgente en la provincia de Guanajuato. Con ella amagaba a los convoyes enemigos en el camino de San Miguel el Grande a San Luis Potosí, enfrentó a los realistas en varias ocasiones en el transcurso de 1815 y posteriormente fortificó el cerro de La Faja, en la sierra de Xalpa, lo cual fue motivo para que uno de los comandantes realistas informara a su superior diciéndole: "Se dice que

40 Joaquín Arias Flores a Rafael Bracho (Celaya, 31 de diciembre de 1817), en AGN, Indiferente virreinal. Apud. Irapuato en la Independencia y la Revolución. Hacia la conmemoración del bicentenario de la Independencia y del centenario de la Revolución. (Irapuato H. Ayuntamiento de Irapuato, Archivo Histórico Municipal, 2009), 19.

41 Pascual Liñán, "Inventario de los papeles tomados en los fuertes rebeldes de Comanja y San Gregorio que pueden servir para conocimiento del excelentísimo señor virrey" (México, 30 de junio de 1818), en AGN, Indiferente virreinal, caja 0683, exp. 039.

42 "Felipe Castañón a Iturbide (San Nicolás, 29 de abril de 1815)", en Boletín del Archivo General de la Nación Vol. XVI, T. III (1930): 132. 
son las gavillas de Valdez, Tovar y Sotero López; pero en mi concepto hay uno que los dirige, porque su marcha, unión y buen orden que conservaron para cargar a nuestra tropa, no ha sido común en esa gente"43.

Otro aspecto que no descuidó el padre Torres en su provincia, fue lo relacionado con los servicios religiosos para todos aquellos que representaban sus bases sociales de apoyo. Tuvo cuidado de no contravenir la orden general del Gobierno Provisional Mexicano del 10 de abril de 1817 que prohibía a los comandantes de las distintas demarcaciones no admitir pase de ningún eclesiástico que saliera de aquellas capitales destinado a algún curato, impidiéndoles la posesión de sus destinos sin dar primero cuenta a aquel Gobierno ${ }^{44}$. En cambio, Torres dispuso que sus tropas dejaran pasar a los padres Mariano Barber y Bartolomé Ortiz a ofrecer a la feligresía el sacramento de la confesión, y que el resto de los eclesiásticos que intentaran pasar fueran arrestados ${ }^{45}$.

\section{El control de los Recursos: Economías de la GUERRILla}

Resultaría inútil decir que, en aquellos años, todo el Bajío y en particular la congregación de Dolores, se convirtió en un territorio en disputa para insurgentes y realistas, no sólo por lo que significaba el control de los principales caminos y rutas de comercio al norte y sur de la provincia, sino también por la variedad de recursos que por allí transitaban provenientes de México y que pasaban por Querétaro, San Miguel el Grande, Guanajuato, Guadalajara y Zacatecas ${ }^{46}$.

Para alimentar a su gente y sostener la insurrección en su demarcación, Torres y sus hombres se aprovechaban de lo que producían las haciendas de Cañada de Negros, Jalpa, Cuerámaro y Corralejo, aunque también llegaron a beneficiarse de lo que había en los pueblos de Rincón, San Pedro y Pénjamo. De las primeras sacaban cantidades importantes de maíz, chile, frijol y otras semillas, mientras que de los segundos se

43 "José Castro a Iturbide (San Miguel el Grande, 11 de marzo de 1815)", en Boletín del Archivo General de la Nación Vol. XVI, T. III (1930): 50; José Miquel, Diccionario de insurgentes, 573.

44 Jaujilla, Michoacán, 10 de abril de 1817), GGPMPP, Genaro García, Documentos T. I, No 2, 11, IV.

45 Pascual Liñán, “Inventario de los papeles", en AGN, Indiferente virreinal, caja 0683, exp. 039.

46 José Serrano, Dolores después del Grito, 33-34. 
abastecían de algodón, aguardiente, herrajes y monturas; con eso bastaba para dar de comer por algún tiempo a los defensores del Fuerte de los Remedios y disponer de un remanente para las temporadas de hastíio ${ }^{47}$.

La carne la conseguían de lo que tomaban como botín en ranchos y haciendas, pero también de lo que lograban arrebatar a algún convoy enemigo. El robo de ganado requería de la participación de un número importante de hombres para poder conducirlo a su destino, pero también de lugares estratégicos desde los cuales pudieran ser mejor distribuidos. Diversos testimonios señalan que en abril de 1814, cientos de partidas insurgentes conducían a Valle de Santiago decenas de cabezas de ganado que habían robado de las haciendas de los alrededores de Celaya ${ }^{48}$.

Los materiales e instrumentos de guerra de los que dispuso el padre Torres tampoco eran despreciables. En agosto de 1814, sin decir nombres, un espía de los realistas informó a sus superiores que "de Guanajuato e Irapuato mandan a Torres cuantas armas y auxilios pueden", especialmente sables, pólvora y metralla ${ }^{49}$. Otro testimonio de mediados de abril de 1815 señala que cuando los realistas se encontraron con la partida del capitán José María Contreras en El Potrero del Capulín, lograron aprehenderlo junto con otras nueve personas que le acompañaban, pero además, le confiscaron 50 caballos malos cargados de fierro. Contreras marchaba desde Ario, Michoacán, y tenía como lugar de residencia dicho Potrero del Capulín; lo más probable es que el fierro que transportaba fuera de la ferrería que los insurgentes controlaban en Coalcomán, y que llevara como destino el Fuerte de Los Remedios, donde el padre Torres disponía de una maestranza, una fundición y otros edificios destinados para la fabricación de material bélico, según se puede apreciar en el "Plano y vista del Fuerte de los Remedios"

47 "Iturbide a José de la Cruz, (Salamanca, 15 de junio de 1814)" en Boletín del Archivo General de la Nación, Vol. XI T. II (1926): 103.

48 (jueves 14 de abril de 1814), en Boletín del Archivo General de la Nación, Vol. XI T. II (1926): 157.

49 "Informe de un espía realista (Apatzingán, 20 de agosto de 1814)", Morelos. Su vida revolucionaria a través de sus escritos, Ernesto Lemoine Villicaña, 480. 
publicado por Mariano Torrente y que posteriormente retomó Lucas Alamán ${ }^{50}$.

Con el dinero que lograban reunir los administradores de haciendas de los insurgentes en su respectiva demarcación, negociaban la compra de importantes cantidades de maíz con los propietarios de la hacienda de La Laja, muy cercana a la villa de León, cuyo producto llegó a ser confiscado por los oficiales realistas en abril de $1815^{51}$. Los rancheros del norte de Guanajuato también apoyaban a los sublevados a cambio de que nos les arrebataran sus animales ni fueran objeto de vejaciones ${ }^{52}$.

Además de las maestranzas y fundiciones establecidas por Torres en el Fuerte de Los Remedios, el flamante teniente general efectivo de la provincia de Guanajuato había logrado montar en las inmediaciones de Valle de Santiago, una modesta maestranza y una carpintería donde los hombres subordinados al coronel insurgente Lucas Flores, se dedicaban a la fabricación de cureñas, cajas de fusil y de pistola, y disponían además de ciertas cantidades de cobre ${ }^{53}$.

Las partidas de guerrilla contaban con su propia tesorería, misma que estaba al cuidado de los hombres de confianza de los comandantes y jefes militares. José María Rodríguez era el tesorero de una de las divisiones rebeldes subordinadas al padre Torres; él era el encargado de remitir a dicho mariscal cantidades importantes de pólvora, aguardiente y algodón que lograba reunir de distintos pueblos y lugares del Bajío. Poco tiempo después, a Rodríguez se le formó sumaria por parte de la justicia insurgente, cuando se descubrió que buscaba el indulto del gobierno $^{54}$.

50 "Felipe Castañón a Iturbide (Cuchicuato, 15 de abril de 1815)", en Boletín del Archivo General de la Nación Vol. XVI, T. III (1930): 121. Alamán, Historia de Méjico, IV, 610-611.

51 "Felipe Castañón a Iturbide (Cuchicuato, 15 de abril de 1815)", en Boletín del Archivo General de la Nación Vol. XVI, T. III (1930): 121.

18852 José Serrano, Dolores después del Grito, 45.

53 Felipe Castañón a Cristóbal Ordoñez (Irapuato, 13 de mayo de 1817), en Gaceta del Gobierno de México, T. VIII, No. 1090, (México, jueves 19 de junio de 1817): 678-679.

54 Pascual Liñán, “Inventario de los papeles...”, en AGN, Indiferente virreinal, caja 0683, exp. 039. 
Vicente Robles era administrador general de las haciendas comprendidas en la comandancia general de San José de los Llanos con sede en la hacienda de Burras, que estaba bajo las órdenes del coronel del Regimiento de Santiago y comandante de aquel punto, José Miguel de Borja, aquel que fungiera como secretario de actas en las asambleas de militares que tuvieron lugar en el Fuerte de los Remedios en los meses de noviembre y diciembre de 1816. J. J. Web en su informe al virrey Apodaca sobre la expedición de Xavier Mina, señala que en esa finca tenía su cuartel y que de esas haciendas provenían la mayor parte de sus recursos ${ }^{55}$.

Rafael Sánchez por su parte, fungía como administrador general de las haciendas de la jurisdicción de León, un personaje difícil de aprehender por los realistas, porque cada noche salía a dormir por distintos rumbos, hasta que fue sorprendido en el rancho de La Sandía junto con su mozo Antonio Basilio y su escribiente Martín Muñoz. Les tomaron toda la correspondencia y varios papeles impresos que remitieron a la autoridad superior, posteriormente los tres fueron fusilados ${ }^{56}$.

De igual modo, en Puruándiro funcionaba otra tesorería a las órdenes del coronel Manuel Vargas Machuca, comandante de aquel punto, quien periódicamente remitía al padre Torres el inventario general de lo recaudado en su demarcación. Además de los tesoreros y administradores, los subdelegados también desempeñaron un rol importante en la captación de recursos y en la distribución de los mismos. José Chávez, subdelegado de los rebeldes en Pénjamo puesto por el padre Torres, prohibió todo tipo de comercio en aquel pueblo desde que empezaba a anochecer.

Torres también echó mano de los comisionados, hombres de su confianza que lograban introducirse en las principales ciudades y villas de la provincia de Guanajuato, como León y la propia capital de aquel Real

55 James Morris Webb, "Informe de la expedición del rebelde Mina al virrey Apodaca. Sucinta noticia de las principales circunstancias pertenecientes a la expedición de Mina contra el Reino de Nueva España", en Diarios Expedición de Mina. México (1817), 166

56 "Gaspar López a Iturbide (Silao, 13 de abril de 1815)", en Boletín del Archivo General de la Nación Vol. XVI, T. III (1930): 109. 
de Minas, con la intención de conseguir recursos y ganar adeptos para la causa. Uno de ellos fue José Gregorio Rodríguez que fue detenido en la hacienda de Burras con un puño de papeles por el comandante realista José María Esquivel Salvago el 31 de marzo de $1815^{57}$. Otro hombre de confianza de Torres - pues era su confidente- fue José María Noriega, dependiente de la casa de don Mariano Otero y ex regidor constitucional en Guanajuato, que luego de ser descubierto fue fusilado y decapitado. Las cabezas de ambos fueron fijadas en dos escarpias a la entrada a la capital, por el camino de la hacienda de Burras ${ }^{58}$. Otro más fue Laureano Guerrero, confidente y emisario insurgente que llevaba cartas a Guanajuato y "daba cuantas noticias podía adquirir, con cuyos aviso frustró el buen efecto de algunas expediciones" que emprendió el coronel Joaquín Villalba, razón por la cual fue decapitado en Guanajuato ${ }^{59}$. Así mismo, como comandante de armas en la zona del Bajío, Torres daba distintas comisiones a su gente, como la que expidió a Dionisio Márquez para que levantara nuevamente su división y diera cuenta a José María Rubio que residía en el Valle de Santiago ${ }^{60}$. Todo esto explica en cierto modo por qué permaneció activa la insurgencia en el Bajío todo ese tiempo, a pesar de haberse creado desde años atrás la comandancia militar de Guanajuato al mando del coronel Agustín de Iturbide ${ }^{61}$.

\section{VARIABLES OPERATIVAS DE LA GUERRILLA}

La guerra de guerrillas en los años de la revolución novohispana remite a un tipo de conflicto que en el léxico contemporáneo los analistas consideran "de baja intensidad". Entiendo la guerrilla como un pequeño grupo armado que conoce a cabalidad el terreno que pisa; que funciona bajo una cierta estructura y que tiene claro por qué luchan; puede ser

57 "Esquivel Salvago a Iturbide (Irapuato, 7 de abril de 1815)", en Boletín del Archivo General de la Nación Vol. XVI, T. III (1930): 108.

58 "Iturbide a Calleja (Irapuato, 21 de abril de 1815)", en Boletín del Archivo General de la Nación Vol. XVI, T. III (1930): 116.

59 "Iturbide a Calleja (Irapuato, 24 de abril de 815)", en Boletín del Archivo General de la Nación Vol. XVI, T. III (1930): 124.

60 Prontuario de los insurgentes. Introducción, Virginia Guedea, 254.

61 Véase: Joaquín E. Espinoza Aguirre, "La imperiosa ley de la necesidad. Guanajuato y la génesis de las comandancias militares novohispanas", Tiempo y Espacio, Vol. XXXVI No. 67, (2017): 176-199. 
por motivaciones patrióticas, pero también por razones políticas o religiosas. No se trata, en este caso, de una masa de hombres que pelean sin bandera: están dispuestos a morir por sus ideales y convicciones, por principios morales y políticos. No olvidemos que tanto la religión como el patriotismo estuvieron muy presentes en su imaginario, y era eso lo que los impelía a luchar y morir, si era necesario.

El análisis que hemos hecho sobre el comportamiento de varios jefes rebeldes en aquella época, como José Guadalupe Salto, Albino García, Benedicto López, Pedro Moreno, Víctor Rosales, Vicente Guerrero y Pedro Asensio Alquicira, nos lleva a sugerir que la lucha guerrillera en Nueva España contra el gobierno virreinal vivió cuatro fases más o menos características: la primera, entre 1810 y 1811, con formaciones primarias de lucha irregular, poco organizada y por lo mismo nada exitosa en el logro de sus objetivos; la segunda, entre 1812 y 1814, con partidas de guerrilla que se mueven en la frontera de lo regular/irregular, ya que se estructuran jerárquicamente conforme a las Ordenanzas militares de España, pero siguen actuando desde el ámbito de lo irregular; la tercera, entre 1814 y 1818, que es en la que se inscribe la guerrilla del padre Torres, se caracterizó por la fortificación de cerros e islotes y la guerra irregular, con partidas mejor organizadas tanto en sus prácticas operacionales como en sus apoyos logísticos; la cuarta y última, es la que correspondería a los años de 1819-1820 con una guerrillas que se mueven por convicción, debido a la persuasión e incluso a la coerción, y en la que figuran Vicente Guerrero, Pedro Ascencio Alquicira, Juan Álvarez y Gordiano Guzmán, entre otros.

Dicho esto, ¿Cómo operaban las guerrillas del padre Torres? ¿De qué manera combatían? ¿Cómo es que lograron sostenerse tanto tiempo? Quizá el testimonio del coronel realista Agustín de Iturbide puede ayudar a entender una de las caras más singulares de las guerrillas comandadas por el padre Torres en esos años, cuyo éxito se basaba en la rapidez de sus movimientos, en el conocimiento que tenían del territorio, en su experiencia como hombres de campo, en la fortaleza y agilidad de sus caballos, en la variedad de estratagemas o engaños que empleaban para sorprender al enemigo y hostigarlo, y desde luego, en el respaldo material y moral del paisanaje. Una carta de Iturbide enviada a Ciriaco de 
Llano ilustra a la perfección lo difícil que era "echarle el guante" a aquel cabecilla. Decía en ella:

"Dije a vuestra señoría a boca, y repito, que a las tropas que tengo el honor de mandar inmediatamente, no pueden imponerse las gavillas del padre Torres, aun cuando se les unan las que existen en la provincia de Valladolid, pues las ven con sumo respeto, como se demuestra claramente por la experiencia: de continuo me paseo con quinientos hombres y si no es valiéndome de muchas estratagemas nunca logro verlas porque jamás me presentan acción; pero esto mismo es un mal, porque con sólo los deseos no pueden ser destruidas; las sigo por una parte y buyen por mil, quedando con su misma fuerza y en disposición de volverse a reunir; de aquí es que si yo no tengo la necesaria para poderlas atacar por tres o cuatro puntos, siempre trabajaré sin fruto" ${ }^{92}$.

Este testimonio coincide con el que meses después proporcionó el cura capellán José María Morales en noviembre de 1815, cuando declaró a las autoridades realistas que el padre José Antonio Torres tenía sus gavillas dispersas por toda la provincia, a cuyos jefes convocaba "sólo cuando se le ofrece alguna expedición [...] porque no siempre las tiene sobre las armas" "63. Eso quería decir que su comandante los podía tener ocupados en sus lugares de origen realizando diversas actividades, o bien trabajando en los baluartes del Fuerte de Los Remedios, edificados en la cima del cerro de san Gregorio desde finales de 1814.

La emboscada fue una táctica muy recurrente entre las filas del padre Torres. Cuando se enteraron que el capitán realista Francisco Linares había pasado por Valladolid y que al día siguiente marcharía a Pátzcuaro, Torres se mantuvo "emboscado en la sierra". El 9 de marzo de 1817 movió su campamento al llano de Chapultepec, en el punto de La Verdolaga y allí distribuyó sus tropas en varios trozos, cubriendo el centro, la izquierda y la derecha; la tropa de reserva quedó a cargo de José María Negrete, a sus coroneles Cabeza de Vaca y Uribe los dejó sin destino

62 "Carta de Iturbide a Ciriaco de Llano (Salamanca, 15 de junio de 1814)", en Boletín del Archivo General de la Nación, Vol. XI T. II (1926): 97-98.

63 Declaración de Morales (México, 24 de noviembre de 1815), en Morelos. Su vida revolucionaria a través de sus escritos, Ernesto Lemoine Villicaña, 611. 
para auxiliarlo ante cualquier eventualidad y para realizar la emboscada al brigadier José María Huerta “por ser su división la más práctica en aquellos terrenos" 64 .

Aunque no fue exclusivo del padre Torres, sí podemos asegurar que el incendio de pueblos, haciendas y ranchos fue algo característico en la actividad guerrillera de los jefes y oficiales bajo su mando. En febrero de 1815 Torres ordenó incendiar cientos de casas así como decenas de haciendas, ranchos y pastos del distrito de Pénjamo ${ }^{65}$; lo mismo ocurrió con Tangancícuaro en junio de 181766; Valle de Santiago en noviembre del mismo año ${ }^{67}$; y Puruándiro, San Felipe, Uruapan, San Francisco del Rincón, Penjamillo, Valle de Santiago y aún el mismo Pénjamo, que era el lugar de su residencia, en febrero de $1818^{68}$. Hubo ocasiones en que las mismas propietarias de algunas fincas rústicas ubicadas en el Bajío, optaron por incendiar sus bienes para impedir que los soldados realistas se abastecieran en ellas. Esto ocurrió con la señora Luisa Herrera, quien en 1815 incendió su hacienda bajo la vigilancia del coronel Encarnación Ortiz.

Las armas utilizadas por las guerrillas del padre Torres consistían en fusiles, pistolas, espadas y lanzas que habían capturado a los enemigos en la refriega; otras las habían reparado en sus talleres, carpinterías y maestranzas que habían establecido en la cima del Fuerte de Los Remedios y en las inmediaciones de Valle de Santiago; y algunas más las fabricaron ellos mismos con el fierro que les llegaba de Coalcomán. Las armas de grueso calibre (cañones, obuses o culebrinas) fueron prácticamente inexistentes para las guerrillas, debido al tipo de guerra que hacían. Con las armas de fuego se tiroteaban con el enemigo atrayéndolo al paraje donde tendría lugar la emboscada; ahí los recibían "a pie firme haciéndoles un fuego muy vivo y sostenido", y cuando Torres se daba cuenta

64 "Torres al presidente y vocales del Gobierno Provisional (campo general en el Llano del Cuatro, 13 de marzo de 1817)", en Documentos históricos mexicanos, Genaro García, T. I, No. 2, 6-8.

65 "Torres a Rosales (Pénjamo, 18 de febrero de 1815)", en Prontuario, Virginia Guedea, 528-529.

66 Lucas Alamán, Historia de Méjico. Desde los primeros, IV, 340.

67 Lucas Alamán, Historia de Méjico. Desde los primeros, IV, 614.

68 Carlos Díaz Barroso a Juan Aragó (Santa Cruz, 9 de agosto de 1818), en AGN, Operaciones de guerra, Vol. 911, f. 108; Alejandro Villaseñor y Villaseñor, Biografías de los héroes, II, 165. 
que aquellos trataban de hacerse fuertes en algún sitio, ordenaba el "toque a degüello" con el arma blanca y al instante todos sus comandantes avanzaban sobre el enemigo "haciendo una horrorosa carnicería" 69 .

Los soldados y otros enemigos de la causa eran fusilados de inmediato, no sin antes brindarles los auxilios espirituales. A las prostitutas que les acompañaban les daban "su estropeada conduciéndolas a pie de un lugar a otro" y luego las ponían en libertad, mientras que las esposas de los soldados fusilados eran destinadas para canje por algunas de las señoras de los insurgentes que Agustín de Iturbide había llevado del Bajío. Esto lo hacían con la finalidad de que sus enemigos imitaran "la observancia del derecho de gentes y de guerra, y para que aprendan a pelear solamente con el valor y las armas".

Todo parece indicar que las armas, monturas, cajones con fusiles, vestuarios, herrajes para caballos y todo el convoy que transportaban decenas de mulas, quedaban a disposición del padre Torres y de los comandantes que habían participado en la acción, pues aunque se daba parte circunstanciado de lo capturado al Gobierno Provisional, no encontramos evidencias con respecto a su destino final. Lo más probable es que se considerara un botín de guerra y que sus jefes y oficiales fueran sus primeros beneficiados.

Hasta donde se ha podido documentar, las formas de lucha de la guerrilla que estudiamos no siempre dependieron del plan de ataque diseñado previamente por el jefe principal, sino por lo que había dispuesto el Gobierno Provisional Mexicano en esta materia. Cuando la guerrilla del padre Torres llegaba a atacar algún pueblo, villa o ciudad de cierta importancia, como Pátzcuaro, por ejemplo, desistía de su intento "por tener expresa orden de vuestra excelencia [el Gobierno] de no empeñar acción contra trincheras, y también porque mi presencia hacía falta en la provincia de Guanajuato". De igual modo, el incendio de pueblos, ran-

69 Torres al presidente y vocales del Gobierno Provisional (campo general en el Llano del Cuatro, 13 de marzo de 1817), en GGPMPP, T. I, No. 2. (Jaujilla, Michoacán, lunes 21-III-1817), en Genaro García, Documentos, t. IV, 6-8. Mientras no se indique otra cosa, la explicación se basa en la misma fuente. 
chos y haciendas, obedecía a una orden expresa girada por las distintas instancias gubernativas de la insurgencia.

\section{El PROYECTO POLÍtico Y LA DEFENSA DE LA INSTITUCIONALIDAD}

A pesar de haber compartido en un inicio, los mismos sentimientos de fidelidad de muchos novohispanos hacia la figura del rey Fernando VII, con el correr de los años y las circunstancias de la guerra, el padre Torres se fue alejando gradualmente de la forma monárquica de gobierno y lo que el soberano representaba con su reincorporación al trono de España. No fue de su agrado que aquel monarca anulara los decretos de las Cortes gaditanas y que aboliera la Constitución Política de la Monarquía Española, con su decreto del 4 de mayo de 1814 dado desde Valencia, España.

Si algo distinguió a los jefes y oficiales que dirigían las guerrillas del padre Torres o que actuaban en combinación con las de él, fue su declarada postura antimonárquica. El padre Torres consideraba que el regreso al trono del rey Fernando VII, luego de su cautiverio en Valençay, significaría "la total ruina de España y de los gachupines de este Continente", postura que asumió aún antes de promulgarse el Decreto Constitucional en Apatzingán ${ }^{70}$. El brigadier Mariano Borja, comandante del departamento de Yuriria, en Guanajuato, vivía con la firme determinación de "ser enemigo del gobierno de este país y cuando no hubiere esperanzas ningunas de prevalecer contra él se fugaría para los Estados Unidos, pues nunca viviría bajo el gobierno de Fernando VII" por considerarlo tirano ${ }^{71}$. De igual modo, el brigadier Pedro Moreno, comandante de la provincia del Potosí con sede en el Fuerte del Sombrero, dijo en la asamblea de generales que tuvo lugar en el Fuerte de Los Remedios en diciembre de 1816, que "siempre ha visto con odio el gobierno monárquico" 72 . Por su parte el coronel y cura insurgente

$70 \quad$ Carta del padre Torres a Pedro Celestino Negrete (Pénjamo, 13 de julio de 1814), en Colección de documentos para la historia de la guerra, Juan E. Hernández y Dávalos, VI, No. 258 (sic) 228-231.

71 James Morris Webb, “Informe de la expedición del rebelde", en Diarios Expedición de Mina. México (1817), 166.

72 Acta de Asamblea de Comandantes Militares (Fuerte de Los Remedios, 13 de diciembre de 1816), en

"El Fuerte de los Remedios", Boletín del Archivo General de la Nación. Vol. 6 No. 1, (enero-febrero de 1935): 92-93. 
Mariano Carmona, defensor del Fuerte de San Miguel de Frontera en la Mesa de los Caballos, consideraba al soberano de España un “imbécil monarca" $"$.

Detrás de estas declaraciones había un claro posicionamiento político: la defensa del sistema republicano de gobierno amparado en el Decreto Constitucional de Apatzingán, sancionado por el Supremo Congreso Mexicano el 22 de octubre de 1814 en aquella población michoacana. Así se acordó en la reunión de comandantes que se juntaron en el Fuerte de los Remedios en noviembre de 1816, con la intención de discutir con Ignacio Rayón los términos en que debía instituirse el gobierno supremo:

"Que el [plan de] gobierno de la Asamblea debía ser: [Lo primero], poner en sus funciones la Junta Subalterna bajo su mismo Reglamento y nuestra Constitución, porque a más de ser a justicia este gobierno, estaba ya reconocido y estará más expedito para funcionar. Lo segundo, porque siendo de absoluta necesidad el establecimiento de un gobierno que reúna siquiera los comandantes comprometidos y no vaya pereciendo cada uno de por sí, el gobierno de la Junta es el conforme al sistema republicano que hemos de seguir, y el que ya tiene avanzados los pasos [...] Y lo tercero [...] que se vea su integridad y puro amor a la patria, sin la más pequeña sombra de particulares miras; pues abrazan y sostienen un gobierno que establecieron otros y que con la misma energía, sostendrán el que establezca por la votación libre y general que se espera con arreglo al sistema republicano" 74 .

El propio José Antonio Torres expresó claramente sus ideas sobre la religión, la libertad, la propiedad, la independencia y la justicia, en aquella carta que remitió al comandante realista Cristóbal Ordoñez desde el Fuerte de Los Remedios, el 20 de abril de 1817 :

73 “Jaujilla, Michoacán, jueves 10-IV-1817)”, en Documentos históricos mexicanos, Genaro García T. I, No. 3, IV, 9-10.

74 Acuerdo de Asamblea de Comandantes Militares presidida por el padre José Antonio Torres (Fuerte de Los Remedios, 6 de diciembre de 1816), en "El Fuerte de los Remedios", Boletín del Archivo General de la Nación. Vol. 6, No. 1, (enero-febrero de 1935): 89-90. 
"Soy católico, apostólico, romano; no me reputo separado del gremio de la Iglesia, no niego alguno de sus misterios, estoy pronto a derramar por cualquiera de sus dogmas hasta la última gota de mi sangre; no he introducido algún cisma, solamente defiendo los derechos de mi Patria; quiero que la América sacuda el yugo español, que salga de la tiranía en que ba estado tres siglos; que sus habitantes sean hombres libres; que seamos dueños de nuestras tierras y sus productos; que seamos independientes; que tengamos cerca de nosotros y con la separación de dilatados mares un gobierno que escuche nuestras quejas; que nos haga justicia y que defienda nuestros derechos sin estar sujetos a unos favoritos venales, extranjeros, que nos tratan como bestias y que sólo cuidan del aumento y consecución del oro mexicano"75.

\section{Desarticulación de la guerrilla y muerte del padre Torres}

A pesar de la toma del Fuerte de Los Remedios, el padre Torres continuó con su actividad guerrillera, lo cual no fue desconocido para los comandantes realistas. A mediados de enero de 1818 Cruz escribió a Liñán desde la Nueva Galicia diciéndole que

"El Valle de Santiago es y ha sido la principal madriguera de los rebeldes y punto de sus reuniones. Casi siempre han evitado los golpes que se les han intentado dar por la multitud de acequias que hay y que no puede vencer la caballería sin llevar puentes. Está quemado como vuestra merced sabrá y no sé si existe algún edificio para alojar la tropa.

Las haciendas de Corralejo, Cuerámaro y Tupátaro con todos los ranchos inmediatos y Pénjamo y Puruándiro han dado mucho que hacer, y el maldito padre Torres ha sacado sumas inmensas desde que se alzó con el santo y la limosna y dominó el país. (Ahora me dicen de Tangancícuaro que estaba con gavilla de ochocientos hombres y que Borja y Lucas Flores le esperaban en las barrancas de Huango con otros quinientos" $"$.

75 El padre Torres al comandante realista Cristóbal Ordoñez (Fuerte de Los Remedios, 20-IV-1817), en AGN, Operaciones de guerra, Vol. 641, fs. 88-89. Agradezco esta referencia a Rogelio López Espinoza.

76 "De la Cruz a Liñán (Guadalajara, 16 de enero de 1818)", en México: Entre la lealtad y la independencia. Correspondencia reservada de los mariscales José de la Cruz y Pascual Liñán (1816-1821), Begoña Cava Mesa (México: Universidad Michoacana de San Nicolás de Hidalgo, Sociedad Mexica- 
Oficiales subalternos del mariscal Liñán aseguraban que la partida de Torres no pasaba de 200 hombres, pero a José de la Cruz le constaba que la tarde del 17 de enero el clérigo michoacano había pasado por Teja, Cuitzeo y Pueblo Nuevo con alrededor de 400 hombres y esos puestos no eran los que le había indicado anteriormente ${ }^{77}$. Semanas más tarde, a inicio de febrero, mandando medio millar de hombres y seguido por Pablo Erdozain, uno de los compañeros de Mina, trató de ayudar al Gobierno Provisional instalado en Jaujilla que estaba siendo sitiado por los realistas, pero fueron rechazados por el teniente coronel Lara retirándose del lugar ${ }^{78}$.

Parece ser que con la derrota y toma de Los Remedios la autoridad del padre Torres vino a menos, situación que se complicó por las represalias que tomó en contra de Lucas Flores, a quien mandó fusilar después de haber comido juntos y jugar a las cartas; sospechaba que quería indultarse y que no hizo lo que debía para ayudar a los defensores de aquel Fuerte. Señala Alamán en su Historia que, sin causa justificada, mandó fusilar a Remigio Yarza, secretario que había sido de la Suprema Junta y del Congreso; pero en la Gaceta del Gobierno Provisional que se publicaba en la Fortaleza de Jaujilla, cerca de Zacapu, se informó al público que tal medida se debió a que el mariscal Yarza quería indultarse. Como quiera que sea, tales acciones le retiraron a Torres la subordinación de Andrés Delgado “el Giro”, quien en abril de 1818, en Puruándiro, acordó con sus hombres desconocer al padre Torres y nombrar comandante de la provincia de Guanajuato a Juan Arago, mismo que fue reconocido por el gobierno que residía en Huetamo ${ }^{79}$.

Por otro lado, las disensiones continuaron entre los distintos cabecillas: Andrés Delgado "El Giro" estaba desavenido con algunos de ellos, mientras que los "Pachones", Mariano Borja y el padre Torres no se dencia. Correspondencia, Begoña Cava Mesa, 174.

78 Lucas Alamán, Historia de Méjico. Desde los primeros, IV, 673-674.

79 Lucas Alamán, Historia de Méjico. Desde los primeros, IV, 680-681. 
ponían de acuerdo con Antonio Huerta. Esta situación fue advertida por el mariscal Cruz quien dijo a Liñán en una carta: "Parece que el padre Torres pide auxilio contra sus rivales. Ya empieza a pasar órdenes para que le paguen la contribución; en su lenguaje manifiesta no estar ya reducido a los cincuenta zaragates que lo acompañaban hace dos meses. No sé si tiene o puede reunir mucha fuerza"80.

El padre Torres murió sin pena ni gloria. Mal querido por la gente de esos contornos por haber arrasado pueblos y rancherías y robado el sustento de sus familias; distanciado del Gobierno Provisional Mexicano; enemistado con muchos que antes le seguían, siempre a salto de mata viviendo en constante zozobra. Murió en el rancho de las Cabras, en las tierras de la Tlachiquera, jurisdicción de Guanajuato, a causa de un lanzazo que le dio el capitán Juan Zamora, en una riña que tuvieron por causa de un caballo, el 12 de noviembre de $1819^{81}$.

\section{REFLEXIONES FINALES}

El período de mayor auge de la guerra irregular en Nueva España es el que corresponde a los años de 1814 a 1818. Después de la debacle del Ejército del Sur dirigido por Morelos, surgieron decenas de cabecillas guerrilleros con mando de tropa que hicieron lo que quisieron en sus respectivas demarcaciones, convirtiéndose en amos y señores de aquellos territorios, aunque subordinados a las instituciones políticas insurgentes emanadas del Decreto Constitucional de Apatzingán. Uno de ellos fue el padre José Antonio Torres, personaje que gracias a su investidura ejerció un gran influjo entre los distintos jefes y oficiales de la provincia de Guanajuato y sus contornos, pero también entre la población negra, india y mestiza de los innumerables pueblos, haciendas y ranchos de esa jurisdicción.

80 "De la Cruz a Liñán (Guadalajara, 23 de enero de 1818)", en México: Entre la lealtad y la independencia. Correspondencia, Begoña Cava Mesa, 189.

81 Mario Gómez Mata, Entre guerrillas y fuertes: la insurgencia en Lagos y el Bajío de Guanajuato (1810-1821). (Guadalajara: H. Ayuntamiento de Lagos 2015-2018, 2017), 221. 
El estudio de la guerrilla del padre Torres ofrece una mirada distinta al de la historiografía que se ocupa de la resistencia armada en esos años, centrada en las figuras de Pedro Moreno y Xavier Mina; contradice los hechos negativos difundidos por Davis Robinson en torno a su persona y disiente de aquellos historiadores que sostienen que en 1816 Iturbide acabó con la insurgencia en Guanajuato, cuando sólo mudó de forma. Uno de los bastiones más importantes de los rebeldes se encontraba en el Bajío, en el cerro de san Gregorio defendido por José Antonio Torres, quien entre los años de 1814 y 1817 se dio a la tarea de fortificar el famoso Fuerte de Los Remedios con la ayuda de muchos hombres, mujeres y niños de las inmediaciones. A pesar de haber sido sitiado y tomado por las fuerzas del mariscal realista Pascual Liñán a principios de 1818, su guerrilla permaneció activa por un año más. Los distintos jefes y oficiales que la conformaban eran personas con las que Torres había tejido una relación de amistad desde antes de 1810; sus bases sociales de apoyo se localizaban en los pueblos, haciendas y ranchos del Bajío, particularmente en la jurisdicción de León y en lugares cercanos a las sierras de Lobos y de Comanja, cuyas personas tenían una calidad étnica y una condición social también distinta. Eran ellos los que lo proveían de dinero, alimentos, material bélico y todo tipo de recursos para mantenerse en pie de lucha.

Pero sin duda, lo que revela el estudio de la guerrilla del padre Torres, además de su peculiar práctica bélica basada en la emboscada, el golpe sorpresa y la quema de pueblos; es la defensa de un proyecto político de tipo republicano, contrario al monárquico absolutista restablecido con el regreso de Fernando VII al trono de España en 1814. Su apego a la Constitución de Apatzingán que había jurado, la promoción de sus principios, así como la subordinación al Gobierno Provisional Mexicano -no la Junta Subalterna como suele confundirse-, creado precisamente bajo los lineamientos marcados por aquel código, es lo que hizo que el ideal republicano se mantuviera vivo por más tiempo recordán-

200 doles su condición de hombres libres, y que las partidas de guerrilla no degeneraran en cuerpos de bandoleros, no obstante el saqueo, el incendio de propiedades y la desunión que hubo entre ellos. 


\section{Bibliografía}

\section{Fuentes primarias}

\section{Archivos}

Archivo Histórico de la Casa de Morelos (AHCM), Morelia - México.

Diocesano-gobierno-registros-correspondencia-1806-1808

Archivo Histórico de la Casa de Morelos (AHCM), Morelia - México.

Diocesano-gobierno-sacerdotes-nombramientos-1800-1805.

Archivo Histórico de la Casa de Morelos (AHCM), Morelia - México.

Diocesano-gobierno-seminario-órdenes-1806.

Archivo General de la Nación (AGN), Ciudad de México - México. Historia

Archivo General de la Nación (AGN), Ciudad de México - México. Indiferente Virreinal

Archivo General de la Nación (AGN), Ciudad de México - México.

Operaciones de guerra.

\section{Publicaciones periódicas}

Gaceta del Gobierno de México. T. VI, No. 682, México, jueves 12 de enero de 1815.

Gaceta del Gobierno de México, T. VIII, No. 1090, México, jueves 19 de junio de 1817.

\section{Fuentes Secundarias}

Alamán, Lucas. Historia de Méjico. Desde los primeros movimientos que prepararon su independencia en el año de 1808 hasta la época presente. México: Fondo de Cultura Económica, Instituto Cultural Helénico, 1985, 5 tomos.

Bakewell, Peter John. Minería y sociedad en el México colonial. Zacatecas (1546-1700). México: Fondo de Cultura Económica, 1976.

Brading, David. Haciendas y ranchos del Bajío. León 1700-1860. México: Grijalbo, 1988.

Brush, James A, James Morris Webb, John Bradburn y Andrés Terrés y Masaguer, Diarios Expedición de Mina. México (1817). Méxi- 
co: edición de Manuel Ortuño Martínez. Madrid: Trama Editorial, 2011.

Cava Mesa, Begoña. México: Entre la lealtad y la independencia. Correspondencia reservada de los mariscales José de la Cruz y Pascual Liñán (1816-1821). México: Universidad Michoacana de San Nicolás de Hidalgo, Sociedad Mexicana de Geografía y Estadística, 2017.

"Correspondencia y diario militar de Agustín de Iturbide, 1810-1813". En Boletín del Archivo General de la Nación. Vol. IX, T. I, (1923): 1-320.

"Correspondencia y diario militar de Agustín de Iturbide, 1814". En Boletín del Archivo General de la Nación. Vol. XI, T. II, (1926): $1-324$

"Correspondencia y diario militar de Agustín de Iturbide, 1815-1821". En Boletín del Archivo General de la Nación. Vol. XVI, T. III, (1930): 1-668.

Decreto Constitucional para la Libertad de la América Mexicana sancionado en Apatzingán a 22 de octubre de 1814. Apatzingán: Imprenta Nacional, 1814.

"El Fuerte de los Remedios". Boletín del Archivo General de la Nación. Vol. 6 No. 1, (enero-febrero de 1935): 77-98.

Escrig Rosa, Josep. "La construcción ideológica de la Restauración en Nueva España (1814-1816)". Historia Mexicana, T. LXIX, No. 4, (2000): 1493-1548.

Espinoza Aguirre, Joaquín E. "La angustiada situación y nunca vista escasez. La guerra de independencia en la provincia de Guanajuato (1810-1816)". En Bicentenario. Revista de historia de Chile y América, Vol. 17, No. 1, (2018): 55-89.

"La imperiosa ley de la necesidad. Guanajuato y la génesis de las comandancias militares novohispanas". Tiempo y Espacio Vol. XXXVI No. 67 (2017): 176-199.

202 Flores Carreño, Iliria Olimpia. Vida cotidiana y violencia durante la guerra de independencia. Guanajuato y Michoacán, 1800-1830. México: Fórum Cultural Guanajuato, 2018. 
García, Genaro. Documentos históricos mexicanos. México: Instituto Nacional de Estudios Históricos de la Revolución Mexicana, 1985, 7 tomos.

Gómez Mata, Mario. Entre guerrillas y fuertes: la insurgencia en Lagos y el Bajío de Guanajuato (1810-1821). Guadalajara: H. Ayuntamiento de Lagos 2015-2018, 2017.

Guedea, Virginia, Prontuario de los insurgentes. Introducción y notas México: Centro de Estudios sobre la Universidad, Instituto Mora, 1995.

Guzmán Pérez, Moisés. El insurgente José María Guadalupe Salto. Vida y martirio. México: Secretaría de Cultura, Gobierno del Estado de Michoacán, Secretaría de Turismo y Cultura, H. Ayuntamiento de Morelia, Instituto de Investigaciones Históricas, Universidad Michoacana de San Nicolás de Hidalgo, 2012.

Hernández y Dávalos, Juan E. Colección de documentos para la historia de la guerra de independencia de México de 1808 a 1821. México: Instituto Nacional de Estudios Históricos de la Revolución Mexicana, 1985, 6 tomos.

Irapuato en la Independencia y la Revolución. Hacia la conmemoración del bicentenario de la Independencia y del centenario de la Revolución. Irapuato: H. Ayuntamiento de Irapuato, Archivo Histórico Municipal, 2009.

Lemoine Villicaña, Ernesto. Morelos. Su vida revolucionaria a través de sus escritos y de otros testimonios de la época. México: Universidad Nacional Autónoma de México, 1965.

Miquel i Vergés, José María. Diccionario de insurgentes. México: Porrúa, 1980.

Moreno Gutiérrez, Rodrigo. "La Restauración en la Nueva España: Guerra, cambios de régimen y militarización entre 1814 y 1820". Revista Universitaria de Historia Militar. Vol. 7 No. 15 (2018): 101-125.

Osorno, Fernando. El insurgente Albino García. México: Secretaría de Educación Pública, 1982. 
Serrano Ortega, José Antonio, “Dolores después del Grito. Estrategias militares insurgentes y realistas en el norte de Guanajuato, 18101821”, Tzintzun. Revista de Estudios Históricos No. 61 (2015): 11-48.

(coord.), El sexenio absolutista, los últimos años insurgentes Nueva España (1814-1820). México: El Colegio de Michoacán, 2014.

Villaseñor y Villaseñor, Alejandro. Biografías de los héroes y caudillos de la independencia. México: Jus, 1963, 2 tomos.

Para citar este artículo: Guzmán Pérez, Moisés. "Práctica Bélica en la 204 Revolución Novohispana: La Guerrilla del padre José Antonio Torres, 1814-1818", Historia Caribe Vol. XV No. 36 (Enero-Junio 2020): 169204 DOI: http://dx.doi.org/10.15648/hc.36.2020.8 